\title{
PENSAMIENTO MÁGICO Y RELIGIOSIDAD EN TORNO A LA ENFERMEDAD: MANIFESTACIONES SIMBÓLICAS Y RITUALES; FUNCIÓN Y SIGNIFICADO.
}

\author{
Rafael Pascuall Martínez, Teresa Beltran Martínez, Fernando Fernández Candela
}

\author{
Enfermeros: H.G.U. Elche \\ E-mail: r_pascual@teleline.es
}

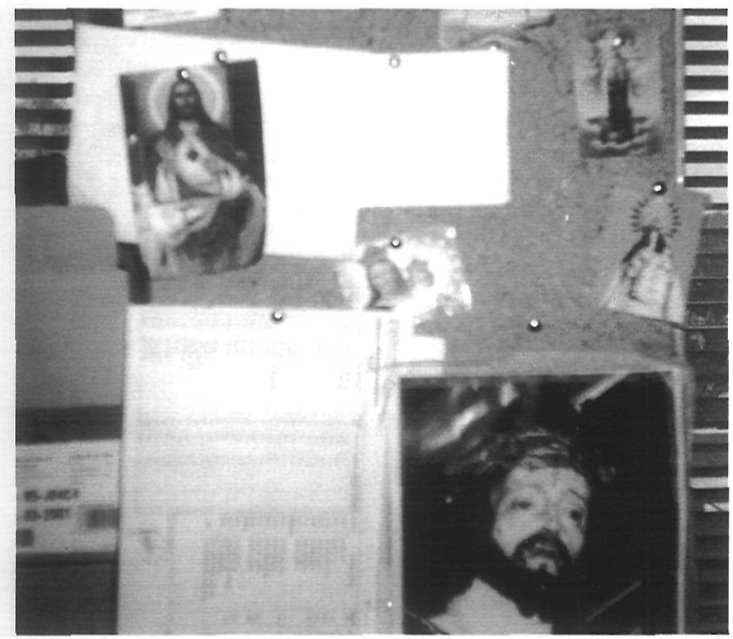

Pequeño altar formado en una unidad de hospitalización.

\section{RESUMEN}

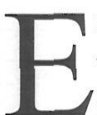

ste trabajo parte de la observación de la convivencia de dos fenómenos de distinta naturaleza como son las creencias y manifestaciones religiosas en el ámbito hospitalario -sobre todo en pacientes, aunque no únicamente- y otras creencias y ritos de tipo "supersticioso" o "sobrenaturales" -observadas en personal sanitario- dentro de un contexto positivista como es el biomédico. El objetivo del trabajo será tanto la descripción de estos ritos y creencias, la forma en la que se manifiestan y difunden, como su significado producto del contexto en el que se desarrollan. La hipótesis es la existencia de una relación entre el significado de estos fenómenos y el contexto hospitalario.

El trabajo de campo, realizado en el HGU de Elche, abarcó desde octubre del 99 a abril de
2000,. Tras el análisis de los resultados se afirma que las imágenes religiosas son un símbolo de identidad colectiva; en su proceso de difusión "intramuros" participan no sólo pacientes y familia, sino también personal sanitario. Se describen una serie de rituales y creencias en el personal como prolongaciones simbólicas propias de una cultura del trabajo. Se llega a la conclusión de que tanto estas como las anteriores tienen la función de satisfacer la seguridad psicológica. El significado de ambos fenómenos guarda relación con el contexto en el que se manifiestan.

\section{MAGIC THINIKING AND RELIGION AROUND ILLNESS: SYMBOLIC MANIFES- TATIONS AND RITUALS, FUNCTION AND MEANING}

his work parts from observation of two coe-
xisting phenomena of different nature: reli-
gious beliefs and manifestations- in a hospital context -mostly but not solely in patients- and other "superstitious" or "supernatural" beliefs and rituals -observed in health professionals- within a positivist context such as the biomedic. The aim of this work will be the description of this rites and beliefs, the way they are demonstrated and disseminated, and their meaning as a result of the context in which they arise. The hypothesis is the existence of a relationship between the meaning of these phenomena and the hospital context.

The field work was carried out at the Elche General University Hospital between October 1999 and April 2000. From the analysis of the results it is pointed out that religious images are a collective identity symbol, in the process of intramural dissemination not only patients and family 
but also health professionals take part. A series of rituals and beliefs of the staff are described as symbolic extensions within the culture of the job. The conclusion is that all of them serve the function of fulfilling psychological security needs. The meaning of both phenomena is in close relation to the context in which they are manifestated.

\section{INTRODUCCIÓN}

ratar conjuntamente las creencias religiosas
de los pacientes junto con otra serie de ritos
y costumbres, digamos que "folklóricos" (manías personales y colectivas, leyendas de fantasmas, supersticiones etc. en el personal sanitario) puede parecer no sólo irrespetuoso sino también incoherente. Pero es su convivencia dentro de un contexto positivista como es el biomédico es el motivo por el cual aparecen englobados dentro del mismo trabajo. Porque es precisamente el contexto en el que se manifiestan el que nos va a dar la perspectiva desde la que van a ser observados e interpretados esta serie de fenómenos objeto de estudio. Si la cultura, según Geertz, es un contexto dentro del cual pueden describirse toda una serie de fenómenos de manera inteligible, no bastará sólo con la descripción de la acción (ritos, símbolos...) sino explicar también el significado que tienen dentro de ese contexto. No obstante, debido a las diferencias en la naturaleza de ambos -religiosidad y creencias de tipo "supersticioso" o sobrenaturalserán tratados en dos capítulos distintos aunque interrelacionados. El objetivo del trabajo será tanto la descripción de estos ritos y creencias, la forma en que se manifiestan y difunden como su significado producto del contexto en el que se desarrollan. Se pretende, así, describir las formas típicas de pensar y sentir que corresponden a la institución y a la cultura de una comunidad determinada (Malinowski, 1995 [1922]: 40). La hipótesis será pues la existencia de una relación entre el significado de estos fenómenos y el contexto hospitalario.

\section{POBLACIÓN A ESTUDIO}

La población objeto de estudio la componen los pacientes y el personal del Hospital General Universitario de Elche. Este hospital, inaugurado en 1978 atiende a la población de Elche, Santa
Pola y Crevillente. Además, es hospital de referencia de Oncología y Neurocirugía para la Vega Baja.

La ciudad de Elche es, en cuanto a número de habitantes (191.812, según el padrón de mayo de 1996) la tercera ciudad de la Comunidad Valenciana. La actividad económica es la industria del calzado, que tuvo su máximo esplendor en los años 60; fue por esto un foco de atracción para inmigrantes del centro y sur de España (Castilla La Mancha, Extremadura y Andalucía), lo que motivó un importante crecimiento demográfico que ha repercutido de forma importante en muchos aspectos culturales.

\section{MÉTODO. EL TRABAJO DE CAMPO}

Los tres componentes del equipo de trabajo son enfermeros de dicho hospital, lo que supone unas condiciones inmejorables para la observación participante. De esta manera las posibilidades de obtención de información se amplían (no únicamente relegadas a cuestionarios más o menos formales) y el riesgo de sesgo por saberse los informantes objeto de estudio por parte de un "profano" es menor. Las técnicas utilizadas para la recopilación de datos han sido:

- Observación directa, que permite prestar atención y recoger ciertos detalles de la vida cotidiana, registrando lo observado tal como lo vemos. Los datos recogidos no fueron únicamente los estrictamente relacionados con el tema de estudio, sino también otros aspectos (como por ejemplo las relaciones entre pacientes, distribución física del hospital, organización social, etc. ) que pudieran ofrecernos una visión global del contexto en el que se desarrollan tales ritos y creencias.

- Observación participante. Es decir, tomar parte en la vida de la comunidad al tiempo que se estudia, lo que facilita la comprensión de los hechos o procesos que estamos estudiando. Por nuestra condición de trabajadores de dicho hospital, no podíamos "escapar" a este tipo de observación. En nuestro caso ha supuesto una ventaja, pues no sólo nos hemos ahorrado esa primera fase de toma de contacto con la institución que hubiera supuesto para alguien ajeno a ésta, sino que, como se ha mencionado anteriormente, se disminuye el riesgo de sesgo en le información obtenida.

- Conversaciones más o menos formales con 
los "actores" para recabar información de interés. No siempre se ha comunicado al interlocutor nuestra intención de realizar un informe con toda esa información que nos proporciona. Es decir, los informantes no debían saber exactamente qué estábamos estudiando: encubrir los interrogantes reales de la investigación para reducir la inhibición de las personas y la amenaza percibida (así evitamos que, por ejemplo, oculten información al observador). Además, presentarse como extraños ingenuos pero interesados (por ejemplo, ante las imágenes religiosas que tiene un paciente en su mesilla) constituye un modo eficaz de obtener datos (Taylor y Bogdan, 1986: 66-67).

- Entrevista pautada, con cuestionario en el caso de las costumbres y creencias en el personal del hospital, para asegurarnos una información completa y comparable de los aspectos de interés del estudio.

Toda la información recogida, todas las observaciones e impresiones percibidas por cada uno de los tres miembros del equipo, se plasmó en sus respectivos diarios de campo. Estos diarios contienen toda la información que será vertida en el informe final de todo el trabajo. Contienen también las tablas que clasifican los datos obtenidos para su mejor análisis. Paralelamente se realizó un análisis de las manifestaciones religiosas en la ciudad que nos muestra la existencia de una marcada relación entre medio natural, economía, fiestas, religión e identidad colectiva en la ciudad de Elche. El tiempo de observación comprende desde octubre de 1999 hasta abril de 2000.

\section{$1^{\circ}$ PARTE}

SÍMBOLOS RELIGIOSOS EN EL HOSPITAL

Circula en el ámbito hospitalario una frase, a medio camino entre el chascarrillo y la observación etnográfica según el cual "el número de estampitas que tiene un paciente consigo es directamente proporcional a la gravedad de su enfermedad". La religión es -para las personas adscritas a alguna religión - una cuestión que afecta al sentido de la vida en su totalidad: re- ligación a Dios y sentido de la existencia son dos temas íntimamente enlazados que, en situación de pérdida de la salud e incluso amenaza de la propia vida, cobra un nuevo sentido, un nuevo peso específico en la vida de una persona. De ahí, por tanto, que no sea extraño - más bien frecuente- observar en personas hospitalizadas la exteriorización manifiesta de su propia religiosidad mediante la exposición de símbo-

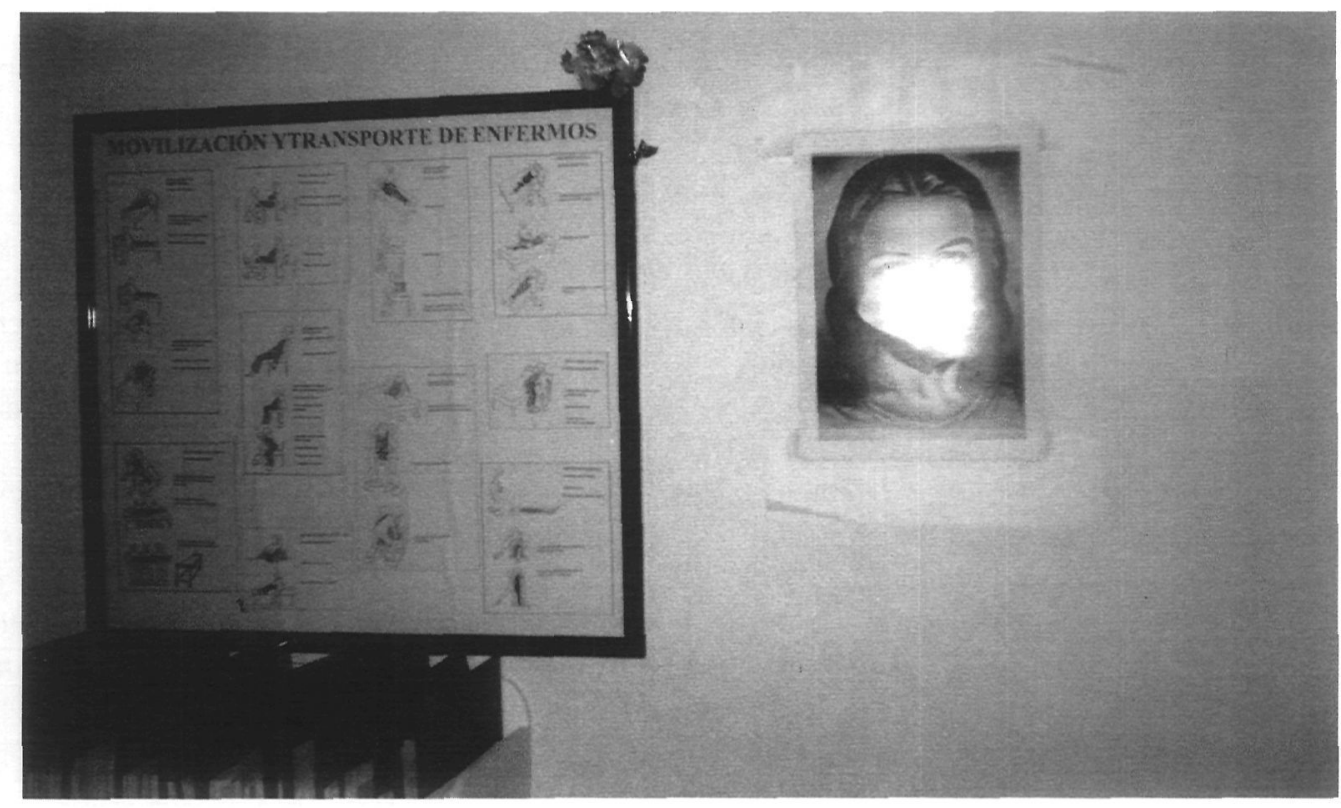

Las imágenes religiosas están integradas dentro del contexto hospitalario. 
los e imágenes religiosas con un propósito que, a priori, se supone que es la intermediación de santos y demás figuras sagradas en su proceso de curación y/o alivio, en clara convivencia con todo ese despliegue científico y tecnológico que utiliza la institución hospitalaria para los mismos fines. Por lo menos, si esta última es incapaz de ofrecer dicha curación, al menos la religión ofrece la esperanza de una vida mejor: de seguir viviendo, en definitiva. Este es un aspecto que críticos de la religión, como Marx y Feuerbach, han considerado como sostén de las religiones. Para Feuerbach, la persistencia de lo que llama "miseria real" hará que la protesta en contra de la misma continúe desembocando en la esperanza de un mejor "más allá" (Eliade, 1996: 545).

\section{DIMENSIÓN SOCIAL Y CULTURAL DE LA RELIGIÓN. DE LO INDIVIDUAL A LO COLECTIVO Y VICEVERSA}

Hay que decir que, si en un principio el principal interés -y casi único- en esta parte del estudio estaba dirigida hacia las manifestaciones individuales de la religiosidad en los pacientes, una vez "entrenado el ojo" a captar todos aquellos aspectos relevantes susceptibles de ser observados, analizados y traspasados al cuaderno de campo, comenzaron a aparecer toda una serie de símbolos religiosos formando parte del hospital: crucifijos, belenes, pósters de alguna divinidad etc. que revelaba que esa coexistencia entre ciencia y religión no sólo era puesta en escena por los pacientes, sino también por la misma institución y su personal. Se comienza por tanto a desvelar uno de los interrogantes planteados al inicio del trabajo de campo: la interrelación entre el contexto, su cultura y la religión.

Para Geertz (1990: 94) los estados de ánimo que provocan los símbolos sagrados, en diferentes épocas y en diferentes lugares, van desde el entusiasmo a la melancolía, desde la confianza en uno mismo a la autoconmiseración, desde una incorregible y alegre ligereza a una blanda indiferencia. Toda esta serie de características, que dan a tales imágenes la condición de símbolos, es el hecho que motiva el considerarlos como fenómenos de interés susceptibles de estudio y análisis. Pero junto a esa serie de sentimientos y motivaciones individuales, de carácter emic, hay que considerar la génesis de estas creencias y representaciones en el seno de una sociedad. Durkheim (1998 [1916]: 263), considera que las categorías de orden religioso deben ser también asuntos sociales y producto del pensamiento colectivo. Durkheim considera a la religión como algo eminentemente social: las representaciones religiosas son representaciones colectivas que expresan realidades colectivas; los ritos son una forma de actuar que no surgen sino en el seno de grupos reunidos, y que están destinados a suscitar, a mantener o rehacer ciertas situaciones mentales de esos grupos. De hecho, y como se verá más adelante, existe una estrecha relación entre las manifestaciones individuales de esa religiosidad y el contexto global de la ciudad: sus fiestas, artesanía, medio físico, iconografía popular... que, volviendo a Geertz, defiende la idea de que toda esa serie de símbolos ha de ser interpretados en función de ese contexto que les da significado. En esto es fundamental considerar las manifestaciones religiosas regionales como un elemento con capacidad de dotar de identidad propia a comunidades y pueblos, aun perteneciendo éstos a la misma confesión (un ejemplo claro lo encontramos en la variedad de celebraciones que cada comunidad hace en Semana Santa, o la identificación de diversos pueblos con distintos santos patrones), siendo esta marca de identidad uno de los elementos de integración en dicha sociedad.

\section{MÉTODO}

Para la recogida de información referente a las manifestaciones iconográficas relacionadas con creencias religiosas en el hospital, con particular interés en las concernientes a las observadas en los pacientes ingresados, el método utilizado ha sido el de la observación participante, apoyado en entrevistas informales con una mínima estructuración. La información obtenida sobre las imágenes religiosas observadas se vertía en unas fichas que recogían los siguientes ítems: nombre de la imagen; formato; localidad a la que pertenecen; propietario; ubicación; proveedor; comentarios.

\section{RESULTADOS}

Veintidós de las imágenes "censadas", bien en forma de estampa, figura o medallas se han obser- 
vado en pacientes; 26 se han registrado en carros de limpieza y 17 formando parte de la decoración del hospital. En cuanto a la imaginería presente en el hospital, resultaría difícil hacer una cuantificación exacta, pues en cada habitación suele haber un crucifijo (los que se rompen no se reponen) y además en Navidad cada unidad suele poner un belén y otros elementos alegóricos, por lo que estaría sujeta a ciclos estacionales.

La observación de las estampas del carro de la limpiadora nos aporta datos sobre la localidad de imágenes que en su día pertenecieron a un paciente. Más adelante se comentará la figura de la limpiadora como elemento de difusión.

De un total de 50 figuras, 32 pertenecían a santos de las poblaciones atendidas por el hospital (siendo mayoritaria la Virgen de la Asunción -7-); y el resto repartido de la siguiente manera: Lourdes: 4; Fátima: 3; Orito/ Monforte: 4; Otras poblaciones: 13; Imágenes "genéricas" (no representan a ninguna virgen o Cristo de una localidad en particular): 5

\section{COMENTARIOS}

Parece evidente la relación que existe entre las imágenes religiosas observadas en el hospital y la procedencia de los pacientes, que en la mayoría de los casos es la misma ciudad en la que se ubica el mencionado centro sanitario.

Junto con estas conclusiones se adjunta el cuadro que contiene todas la información recogida directamente del campo de observación.

\section{Regionalidad}

Junto con estas imágenes de carácter local, llama la atención la existencia de otras que, perteneciendo a una región distinta a la de estudio, se han "nacionalizado" (la "Pilarica" o Fray Leopoldo de Alpandeire) e incluso traspasado las fronteras de su país de origen, como el caso de Fátima o Lourdes, por distintos procesos de difusión.

El hecho de que estas imágenes correspondan en gran número de casos a santos "locales", demuestran en valor que tienen como símbolos de identidad de un pueblo. En ocasiones se les suele adjuntar elementos típicos de la ciudad como palmas en el caso de imágenes ilicitanas o, por ejemplo, motivos marineros (conchas, caracolas...) a una figura de la Virgen de Santa Pola. La única Santa Faz que se observó (imagen de Alicante), la trajo una limpiadora alicantina.

\section{Valor simbólico}

La función simbólico- religiosa de estas imágenes varía dependiendo del contexto en el que se ubican. Por ejemplo, no tiene el mismo significado una figura de San Pancracio con una rama de perejil y cinco duros en el dedo en la vitrina de un bar (símbolo de "salud, suerte y trabajo"), que esa misma imagen con la misma moneda en la mesilla de noche de un paciente, como se pudo registrar durante la observación de campo: el significado que tenía para esta persona era bien distinto al que se le asocia en un contexto más global, pues ahora la "misión" de este santo era la de ayudar en el proceso de curación de este paciente. Sin embargo, un póster de este mismo santo en la sala de estar del personal de urgencias (también con cinco duros pegados con esparadrapo al dedo) vuelve a tener su significado original y más difundido de proporcionar suerte y dinero.

Un claro ejemplo lo pueden constituir las aleluyas. Estas imágenes que son lanzadas desde los balcones en Semana Santa al paso de la Patrona de la ciudad en su honor, comenta una familiar de un paciente ingresado que, cogidas al vuelo por un estudiante, podrán ser utilizadas para aprobar un examen si las pone entre las páginas de su libro de texto: sin embargo, la intención con la que se utilizan dentro del hospital es bien distinta. Por tanto observamos que el contexto modifica el significado de los símbolos.

Las imágenes utilizadas por los pacientes eran usadas -según las conclusiones del trabajo de campo- por su capacidad de mediación en el proceso de curación o mejoría. Pero no se ha de pensar en esta función como una virtud exclusiva de tales símbolos: la exposición de éstos por parte de pacientes muy graves o terminales o por sus familiares puede entenderse como una exteriorización del duelo de éstos y en relación con el periodo de margen -entre la vida que se abandona y la siguiente, dependiendo de las creencias- en el que se encuentra el enfermo. Es decir, por una parte expresaría una aceptación de la situación y por otra una separación del entorno (familiar, social, etc...) 
para agregarse en breve a ese otra realidad que representan las imágenes de las que se ha rodeado el paciente (o sus acompañantes). Durante el periodo de observación no se dio ningún caso de este tipo, aunque la experiencia profesional previa nos permite formular esta hipótesis. De este modo, la manifestación de ritos de margen (o de paso', en un sentido más amplio) como en la situación descrita -y por qué no, su implicación en el plan de cuidados- queda abierta como un nuevo tema de investigación.

\section{Proveedores y difusión intramuros}

La utilización de estas imágenes no es exclusiva de los pacientes ingresados. Las peculiares y estrechas relaciones entre los pacientes y entre éstos y el personal hospitalario es otro factor de difusión de tales imágenes. Los principales difusores de imágenes son los familiares de los pacientes: en todos los casos observados han sido los parientes y amigos (excepto en uno) los que han traído la imagen del exterior. Así, la imagen que aparece en la cabecera de la cama es indicador no tanto de la devoción del paciente hacia esta sino de la identificación que con dicha imagen tiene el familiar que introduce dicha imagen dentro del contexto hospitalario (por ejemplo, el santo de la cofradía a la que pertenece o es devoto dicho familiar). En otros casos, el familiar o el paciente muestra abiertamente la "fe que le tiene" el propio enfermo a tal imagen.

Una vez que el paciente finaliza su estancia en el hospital (bien por alta, bien por éxitus), la imagen entrará en un circuito propio de un proceso de difusión o enculturación. En algunos casos, las "estampas" son entregadas a otro paciente que no es necesariamente el de la cama adyacente, pues puede ser de otra habitación con el que haya entablado relación. Si tras abandonar el paciente la habitación las imágenes permanecen donde éste las dejó, en la mayoría de los casos serán recogidas por la limpiadora, que las colocará en el carrito donde llevan el material de limpieza. Es entonces cuando esta limpiadora puede actuar como un elemento de difusión al entregar algunas de estas imágenes que ha recogido a otros pacientes, aunque también pueden permanecer por largo tiempo en este carro o bien pasar a formar parte de un pequeño "altar"2 que tienen las limpiadoras en el cuarto donde guardan todo su material. (este "altar" está actualmente visiblemente menguado debido a que a una limpiadora le tocó la lotería estas Navidades y se llevó gran parte de estas estampas).

Otras veces las estampas son regaladas al personal o bien recogidas por éstos. Cuando esto ocurre, las imágenes quedarán expuestas a la vista del público o bien pegadas en una pared. Cuando son acumuladas en una pared, poco a poco se irá formando una especie de "altar". Por ejemplo, en la $2^{\text {a }}$ planta (Oncología), hay uno de estos pequeños altares en la zona del sucio formado por estampas recogidas por las enfermeras al alta de los pacientes (foto 1). La explicación que da el personal sobre el hecho de que estas imágenes en lugar de tirarlas se conserven es la posibilidad de que su anterior poseedor pueda reclamarla, aunque la verdad es que a pesar del tiempo transcurrido nunca llegan a deshacerse de ellas. En el servicio de Reanimación hay un altar de similares características formado por imágenes recogidas al alta y regaladas por pacientes. Se puede interpretar esta actuación del personal como una muestra de respeto hacia el hecho religioso y hacia las creencias de los pacientes, pues aunque algunos se han manifestado ateos al ser preguntados sobre este tema, dicen respetar profundamente estas creencias, por lo que no serían capaces de tirar unas imágenes dejadas por un paciente al alta.

Otras veces las imágenes son traídas por el personal que, o bien la expone en la sala de estar de enfermería o en el control cara al público. Un ejemplo es "el Cristo de la $3^{\text {a" }}$ (foto 2), una imagen de Jesús colgada de la pared del control de la $3^{\text {a }}$ planta (Cirugía) que dejó como recuerdo una

' Descritos por Van Gennep (1986 [1908]). A grandes rasgos, estos ritos de paso se dividen en tres categorías con un orden cronológico: de separación, de margen y de agregación. La función de las imágenes mencionadas como manifestación de un ritual de paso, estaría, según esta hipótesis, dentro de las dos primeras.

2"Altar" es el nombre con el que se suele designar a estos espacios caracterizados por la acumulación de imágenes religiosas. 
enfermera que se trasladó en 1997 a otro hospital. Se transcriben estas anotaciones del diario de campo:

"(...) El personal nos cuenta que los pacientes y familiares piden autorización para tocarlo, e incluso un conductor de ambulancia se hizo una fotocopia de ella "porque era el Cristo más bonito que había visto en su vida", según dijo. Una enfermera, al "provocarla", diciendo que podrían quitarlo, dijo que era "precioso, precioso". El personal del turno de la tarde nos dijo que "les ilumina y no les molesta". Al día siguiente de hacerle una fotografía, un enfermero que le tiene mucha devoción [en el original se utiliza su nombre] le puso un marco (...)".

Otro elemento de difusión es el sacerdote del hospital, que en sus visitas a pacientes en ocasiones entrega a éstos alguna imagen.

\section{Ubicación}

La imagen suele colocarse en la mesita de noche, cabecera de la cama o ventana de la habitación. En la planta de Traumatología nos comenta el personal que las suelen poner junto al miembro fracturado, de modo que "puedes ir a hacer una cama y al tirar de la sábana te aparece una estampa".

Vease este ejemplo de la relación parte afectada- ubicación de la imagen: Una enfermera que nos confiesa su fe por Fray Leopoldo de Alpandeire cuenta que cuando su padre tuvo un accidente de tráfico hace diez años sufrió un traumatismo cráneo- encefálico y una amiga de su madre le trajo una estampa de éste fraile: se la pasaban por la cabeza, y después se la dejaban debajo de la almohada. Ante el asombro del médico, "porque no daba un duro por él", nos cuenta, empezó a despertar del coma. Su hija en ese momento no hizo promesa, pero más tarde fue a Granada (localidad del santo) con su marido: fue a ver la tumba y trajo estampas que repartió a amigos y familiares. La imagen de este santo fue también utilizada por esta enfermera en su examen de conducir: esto puede servir también de ejemplo de cómo la función de estas imágenes varía dependiendo del contexto en el que se presenten, aun utilizadas por la misma persona.

\section{$2^{a}$ PARTE CREENCIAS Y RITUALES}

Hay un cuento de Mario Benedetti en el que un hombre que acaba de ingresar a su esposa comienza a realizar "juegos de superstición": si el número de baldosas es impar, ésta se salvará, lo mismo que ocurriría si sonaba la campanada del reloj antes de contar hasta diez. Si bien la actitud de este personaje ficticio es más bien propia de un trastorno de tipo obsesivo- compulsivo, los elementos de la situación y del contexto hacen este comportamiento en cierto modo explicable.

Del mismo modo, si escucháramos decir a un grupo de trabajadores de un hospital que una persona de determinado servicio es tachada de "gafe", o que ingresar en una habitación determinada trae "mal fario", podríamos llegar incluso a dudar de nuestra integridad al ser llevados a dicho hospital. Sin embargo, analizando las características del contexto en el que estas creencias se desarrollan se pueden llegar incluso a calificar de saludables o lógicas. De nuevo es el contexto el elemento que nos ayudará a comprender una serie de símbolos y ritos que a la vista de cualquier persona ajena resultarían extraños. Si el trabajo humano tiene prolongaciones simbólicas que podemos encontrar en diversas manifestaciones -canciones, cuentos, creaciones plásticas, slogans, etc.- (Palenzuela, 1995: 18), este ámbito laboral, como toda actividad humana, no es ajeno a tal hecho. El contexto hospitalario, por sus peculiares características, es una fuente de amplia producción de elementos de este tipo: chascarrillos, leyendas, manías personales y colectivas... que no tienen ningún sentido tomadas de forma aislada pero que estudiadas en función de su contexto de origen son un valioso elemento de información etnográfica, y no meros elementos propios de una especie de museo de "rarezas y curiosidades".

Gran parte de estas creencias y rituales eran conocidas por nosotros debido a nuestra relación laboral con el contexto sanitario. Partiendo de este conocimiento previo, se tratará de contrastar dichas creencias con el personal del hospital. Las entrevistas efectuadas consistían en unos cuestionarios anónimos estructurados en los que se formulaban una

${ }^{3}$ Benedetti, M.: Sábado de Gloria. En Cuentos Completos 1947- 1994. Alfaguara. $7^{\text {a }}$ ed. Barcelona 1998. 
serie de preguntas abiertas, de manera individual y pidiendo al concluir la entrevista que no comentara los ítems con el resto del personal, para evitar que conocieran el contenido del cuestionario antes de ser entrevistados. Las personas encuestadas fueron elegidas al azar de entre el personal de todo el hospital. Se ha procurado, en la medida de lo posible, tomar las frases textuales de los entrevistados, pues obtener unos resultados cualitativos ha primado sobre la cuantificación numérica de las observaciones, pues es la dimensión cultural de los resultados donde se centra nuestro principal interés.

\section{RESULTADOS DE LAS ENTREVISTAS ESTRUCTURADAS}

Se realizaron un total de 31 entrevistas, de las cuales 7 de ellas correspondían a varones y 24 a mujeres. Esta diferencia de género se justifica debido al mayor número de mujeres que trabajan en el hospital.

Del total de los entrevistados corresponde a las siguientes categorías profesionales, 16 personal de enfermería, 11 a auxiliares de enfermería y 4 a otros estamentos. Se comentarán a continuación las preguntas realizadas, aportando tanto los resultados como su interpretación.

1.- ¿Qué piensas si cuando entras a una habitación con enfermos, ves una mosca rondando una de las camas?

\section{MUERTE DEL PACIENTE: 20}

FALTA DE HIGIENE / SUCIEDAD: 9 OTROS: 2

TOTAL: 31

Existe una creencia hospitalaria según la cual la presencia de un insecto, generalmente una mosca, en la habitación de un paciente es un signo de mal presagio ya que indica que a ese paciente le quedan pocas horas de vida.

Nueve de los encuestados asocian este hecho con unas malas condiciones higiénicas del paciente o del entorno que atraerían a los insectos.

Sin embargo para la mayoría de los encuestados la relación causa efecto no tiene una explicación científica siendo esta más bien de orden mágico o sobrenatural, incluso las apoyan con frases cómo: "¡Tate!, qué poco le queda a éste" o "Mal presagio, me huele mal, que el enfermo esta a punto de palmarla" o "Mal agüero, veo la cosa no muy clara..., esas moscas grandes y gordas, que casualidad".

2.- Si tuvieras que ingresar a un familiar cercano a ti en esta unidad (con posibilidad de elegir habitación), ¿Cuál de ellas no elegirías? ¿Por qué?.

\section{SÍ, ELEGIRIA HABITACION: 10 \\ NO ELEGIRIA HABITACION: 5 \\ CAUSAS AMBIENTALES \\ (CERCANÍA AL CONTROL, VISTAS ...): 16}

Se puede definir la habitación "mal fario" como aquella en que un paciente tiene más probabilidades de fallecer incluso a veces independientemente del estado de salud de éste.

Para poder constatar esta creencia en el personal además de la inclusión de este ítem en la entrevista hemos comparado la casuística de éxitus por habitaciones de cada planta del hospital para verificar si realmente esas habitaciones "gafes" corresponden con las que presentan mayor número de éxitus: tras la consulta al personal de las unidades $1^{\mathrm{a}}$. $2^{\mathrm{a}}, 3^{\mathrm{a}}$ y $5^{\mathrm{a}}$ planta sobre cual es la habitación "más gafada" del servicio, se consulta el registro de éxitus en el año 1999 viendo que no existía relación directa entre habitación y frecuencia de éxitus.

Podemos interpretar que el paso por determinada cama de un paciente con una patología llamativa o la coincidencia en el tiempo de más de una defunción consecutiva en la misma habitación puede dejar en el personal un mal recuerdo que llevaría a una asociación inconsciente entre posibilidad de morir y habitación designada.

Posteriormente habría un proceso de difusión a través de comentarios entre compañeros y contraste de experiencias similares que alimentaria el mito de la habitación "mal fario".

La mayoría de los encuestados elegirían habitación en función de su cercanía al control de enfermería, vistas, zonas de paso... Sin embargo una parte de ellos si que pedirían otra habitación aludiendo a la mala suerte que podría traer el ingresar en ellas. Un ejemplo: uno de los encuestados nos dice al respecto "Ni la seis ni la trece porque están en época gafada", "(...) ni el veinte ni el veintiocho 
ni el treinta, en esas habitaciones es dónde más enfermos se mueren".

3.- ¿Encuentras alguna relación entre el número de estampas que tienen los enfermos en su habitación con respecto a la gravedad de la enfermedad?

\section{SÍ EXISTE RELACION: 20 \\ NO EXISTE RELACION: 9 \\ SIN DEFINIR: 2}

Se ha observado en las entrevistas que el personal encuentra relación directa con el número de estampas que tiene el paciente y la gravedad de su enfermedad.

4.- ¿Crees que tiene alguna influencia el hecho de que hayan estampas con respecto a la curación del enfermo?

\section{SÍ EXISTE RELACION: 10 \\ NO EXISTE RELACION: 16 SIN DEFINIR: 5}

Con esta pregunta se observa en que medida confluyen las creencias de los pacientes y del personal, respecto a la función de los símbolos religiosos utilizados en el proceso de curación. Para diez de ellos si que existe una relación bien por el beneficio psicológico que supone para el paciente la práctica de sus creencias o bien por la mediación divina que supone la invocación a dichas imágenes.

5.- ¿Has oído hablar de la "mejoría de la muerte"? ¿Qué opinión te merece?

\section{SÍ: 31 \\ NO: 0 \\ NS/NC: 0}

$\mathrm{Si}$ un paciente en estado grave muestra una mejoría no relacionada con su patología (en muchos casos acompañadas de un aumento del apetito, incluso de una mejoría neurológica) estará experimentando la denominada "mejoría de la muerte": muy probablemente fallecerá en un periodo que puede oscilar desde unas pocas horas a dos o tres días. Esta creencia es firmemente apoyada por la totalidad de los encuestados, los cuales no aportan ningún dato científico que pueda explicar el hecho en cuestión. Algunas de las respuestas han sido:

- "si, sí que existe, lo entiendo como una especie de despedida"

- "es cierto que algunos pacientes están mal y luego mejoran 1 ó 2 días antes de la muerte"

- "sí, la he visto muy de cerca, que es así, hay una mejoría aparente para fallecer después"

- "sí, a partir de las 24 '00 h. realizan ese pase para fallecer a las dos horas"

- "sí que existe, pero no sé a qué es debido"

6.- Si tuvieras que ingresar en una habitación en la que hubieran estampas ¿Qué harías con ellas?.

DEJARLAS: 17

QUITARLAS / TIRARLAS: 5

GUARDARLAS: 5

ENTREGARLAS: 4

Se pretende analizar tanto la influencia que tienen esas imágenes religiosas utilizadas por los pacientes como la percepción que de ellas tiene el personal sanitario. La mayoría de ellos muestra una actitud empática y respetuosa hacia estas creencias representadas por las estampas dejadas por los pacientes al alta, pues son muy pocos los que de ellas se desharían. Algunas frases han sido:

- "las pondría debajo del todo, en la mesita, pero no las dejaría"

- "miraría de qué santos son y si es de alguno que conociera me lo quedaría"

- "no, no las tocaría, me da un poco de yuyu, pero me pondría las mías"

- "soy de la opinión de que todo ayuda, y sobre todo en determinadas circunstancias"

- "las dejaría, porque soy supersticiosa y a lo mejor si las quito me traen mala suerte"

7.- ¿Has observado o conoces algún tipo de superstición o creencia, manía o ritual en el ámbito hospitalario?

SI: 18

NO: 13

Se incluye esta pregunta para tratar de encontrar entre el personal cualquier otro tipo de creen- 
cia que, a pesar de nuestro conocimiento del contexto, pudiera habérsenos pasado desapercibida al elaborar el cuestionario o no conociéramos.

La mayoría de los informantes refiere la existencia de creencias en torno a la presencia de espíritus o fantasmas en el hospital. También repiten algunas de las creencias anteriormente mencionadas, como las consecuencias que supone la presencia de una mosca en la habitación de un paciente en estado grave. Ejemplos:

- "una vez en la dos, se murió un enfermo y los familiares no nos dejaron ni tocarlos; le pusieron una túnica blanca y la metimos nosotros en el sudario: creo que pertenecían a una secta"

- "había una auxiliar que ahora no está trabajando aquí que cuando alguien moría ella decía que veía el espíritu en la habitación"

- "alguna vez me han comentado que en una ocasión un espíritu había repartido la medicación, ya que nadie la había repartido; fue un espíritu, algo etéreo". Esta respuesta está relacionada con la que viene a continuación, pues es la misma historia pero "deformada" a lo largo de su proceso de difusión:

- "en la segunda planta se comentó que había un espíritu que repartía la medicación; salió en un programa de televisión que se llamaba El Más Allá. Una enfermera salió en la televisión diciendo que cuando llegaba a la habitación a dar una medicación, el enfermo decía que una señorita ya se la había dado"

- "se habla de que las almas se quedan dentro, que por las noches se han visto cosas extrañas, el betadine corre por el pasillo, timbres que suenan en habitaciones desocupadas..."

- "hace días que en las llamadas a los buscapersonas aparece el número de la unidad, y el personal no ha llamado: creen en la existencia de espíritus $^{\prime \prime}$

\section{RESULTADOS DE LA OBSERVACIÓN DE CAMPO}

Paralelamente a la realización de estas entrevistas y a su interpretación, se efectuó un registro de estas creencias que podemos calificar de "racionalmente ilógicas", por carecer de base científica, pero que sin embargo forman parte de esta cultura hospitalaria. La observación también se apoyó con entrevistas al personal, pero esta vez sin seguir ningún cuestionario más o menos estructurado, sino entablando una conversación en la que las preguntas iban surgiendo sobre la marcha, en función de la información proporcionada por nuestro interlocutor. Esta fase de observación se realizó en diversas unidades del hospital y a diversas categorías profesionales (enfermería, médicos, pinches...). Da la impresión que al ser "una charla entre compañeros" la información era relatada de una forma más espontanea, tal vez porque el informante no tenía esa sensación de ser encuestado para proporcionar el material necesario para un estudio antropológico. Muchas de estas conversaciones han partido de la observación de comentarios o actitudes entre el personal: datos que eran inmediatamente transcritos al cuaderno de campo.

\section{Creencias y rituales personales}

No todas las creencias de orden mágico o sobrenatural son observables en el ámbito colectivo. Se puede hablar también de creencias o rituales que se manifiestan a nivel individual, y que en su totalidad están relacionadas con el contexto en el que el actor desarrolla su trabajo. Así, por ejemplo, podemos mencionar el caso de una enfermera que nos dice que "cuando a un paciente le hace una limpieza de boca, siempre acaba muriéndose" -hecho corroborado entre sonrisas por una persona presente en la conversación. Otro compañero nos relata:

"cuando un médico, en especial la Dra. M. me dice que le ponga una sonda nasogástrica a un paciente, a pesar de su buen estado físico aparente, ese paciente será éxitus seguro. Lo curioso es que ha pasado más de una vez (una de ellas hace pocos días). Le dije a ese médico: tía, tú eres gafe".

Otra manía personal que se ha observado es el caso de un compañero que en el turno de noche siempre deja cerrada la puerta de la unidad, para 
así tener una buena guardia (dice que es algo así como "cerrar la puerta a aquello que pueda complicar la noche").

\section{Creencias y rituales colectivos}

La creencia más significativa por su frecuencia de aparición durante el trabajo de campo ha sido la existencia del "gafe". El gafe es una persona -médico o enfermera- cuya presencia es señal de que habrá una mala guardia por un exceso de trabajo o una complicación no siempre esperada. En ocasiones el gafe no es una única persona sino la coincidencia de dos personas - generalmente enfermera y auxiliar- en un mismo turno.

Puede darse el caso de que el gafe sea reconocido como tal por un conjunto de personas que, además, al ser preguntadas sobre este hecho, confirman su veracidad basándose en experiencias previas aunque sin poder ofrecer una explicación lógica a este fenómeno. Por lo ilustrativo del caso, se transcribe aquí un fragmento del diario de campo:

"Esta noche estoy en urgencias de Traumatología. Me dicen que el médico de guardia es un "gafe" (me explican: tiene "malas guardias"= guardias de mucho trabajo porque acuden muchos pacientes). Esto me lo advierten varios compañeros/ as, por lo que ya es un sambenito que le han colocado al pobre hombre. Sin embargo la noche es muy buena".

Paralelamente al compañero gafe, se ha observado la existencia de personas que producen el efecto contrario: su coincidencia con ellos en el turno tendrá como consecuencia una carga de trabajo normal e incluso menor a la habitual.

En varias ocasiones y en distintos servicios se ha observado una especie de diálogo estandarizado, también referente a las cargas de trabajo, y que sigue este esquema: alguien menciona lo tranquilo del turno o guardia y a continuación alguien le replica con una frase como "toca madera", "no lo digas muy alto" o "no digas eso, que la última vez que lo dije yo se me complicó la guardia".

Mientras que estas creencias -tanto las descritas bajo este epígrafe como las señaladas en las entrevistas- son compartidas únicamente por personas relacionadas con el contexto hospitalario, las generalizadas en el resto de la población no sola- mente son conocidas por el personal sanitario, sino que han sido objeto de estudio antropológico o sociológico. Estudios sobre la curandería o creencias en torno al nacimiento pueden servir de ejemplo (López Gómez et al., 1999: 52), (Salazar Agulló, 1997: 44). Sobre este aspecto se conversó con un grupo de pediatras que informaron de diversas creencias entre la población relacionadas con el nacimiento y la infancia:

- "Medir": realizado por curanderos. Realizan un rito que consiste en rezar unas oraciones y medir varias veces el antebrazo del niño para "bajar el empacho"

- Lazo rojo, utilizado para el mal de ojo. También se observó uno en el carro de una limpiadora,

- Evangelios: escapularios que se ponen a los niños en pañales y ropa interior para ahuyentar el "mal de ojo".

- Hilo de algodón: se coge un hilo de algodón de la ropa del niño o de su manta, se chupa y se le pone en la frente para que se le pase el hipo. La pediatra que lo cuenta recuerda que "en su época de estudiante una profesora, al explicar un tema relacionado, al principio de su exposición pidió que no le preguntaran por qué funcionaba lo del hilo"

- En Valencia, para que un niño no se hernie, la noche de San Juan lo pasan por debajo de la rama de una higuera.

\section{Espíritus y esoterismo}

Se ha comentado anteriormente la existencia de leyendas de fantasmas circulando en el hospital. La más difundida es la de la enfermera de la segunda. De esta historia se han recogido varias versiones entre el personal del hospital: unos dicen que una noche se apareció ante un paciente al que le dio su medicación; otros dicen que no tiene piernas y que usa un uniforme de los antiguos, o que va con una linterna...

Un compañero relató que una noche "salió despedida del cuarto de la medicación una botella de 
Oraldine hacia la pared de fuera". No da ninguna explicación a este hecho, pero la historia se difundió tomando formas distintas a la original.

También se ha encontrado personal que dice tener algún poder o percepción extranatural, como una auxiliar que dice poder ver el espíritu de una persona recién fallecida o una pinche de cocina, diplomada en ciencias esotéricas, y con cierta fama -nos comentan que apareció en un programa de Canal Sur- y a la que acude personal de todo el hospital para ser consultada.

Comentario de los resultados. Una justificación etic de ritos y creencias.

La lectura de estos resultados elaborados a partir de la información obtenida, a la vista de una persona ajena a los hospitales y su cultura puede ser interpretada como un cúmulo de rarezas que le harían cuestionarse qué tipo de gente trabaja en estos sitios.
Una descripción exclusiva de estos fenómenos pueden producir una visión sobredimensionada de ellos: el pensamiento mágico no es un hecho que impregne la totalidad de la cultura hospitalaria, sino un elemento más producto de ésta, como lo podría ser el tipo de asociaciones que surgen de este contexto o la estructuración social dentro del hospital, por ejemplo.

La tensión que puede surgir en este ambiente laboral debido a las características del objeto de trabajo y de la responsabilidad que genera, además de factores no siempre agradables que lleva consigo (dolor, enfermedad, muerte...), produce una serie de creencias relacionadas con su evitación (de ahí el interés por tener buenas guardias). La muerte, como un elemento en ocasiones cotidiano de este contexto, genera una serie de leyendas, ritos y actitudes que no se producirían, como es natural, en otro ambiente laboral de modo que, de

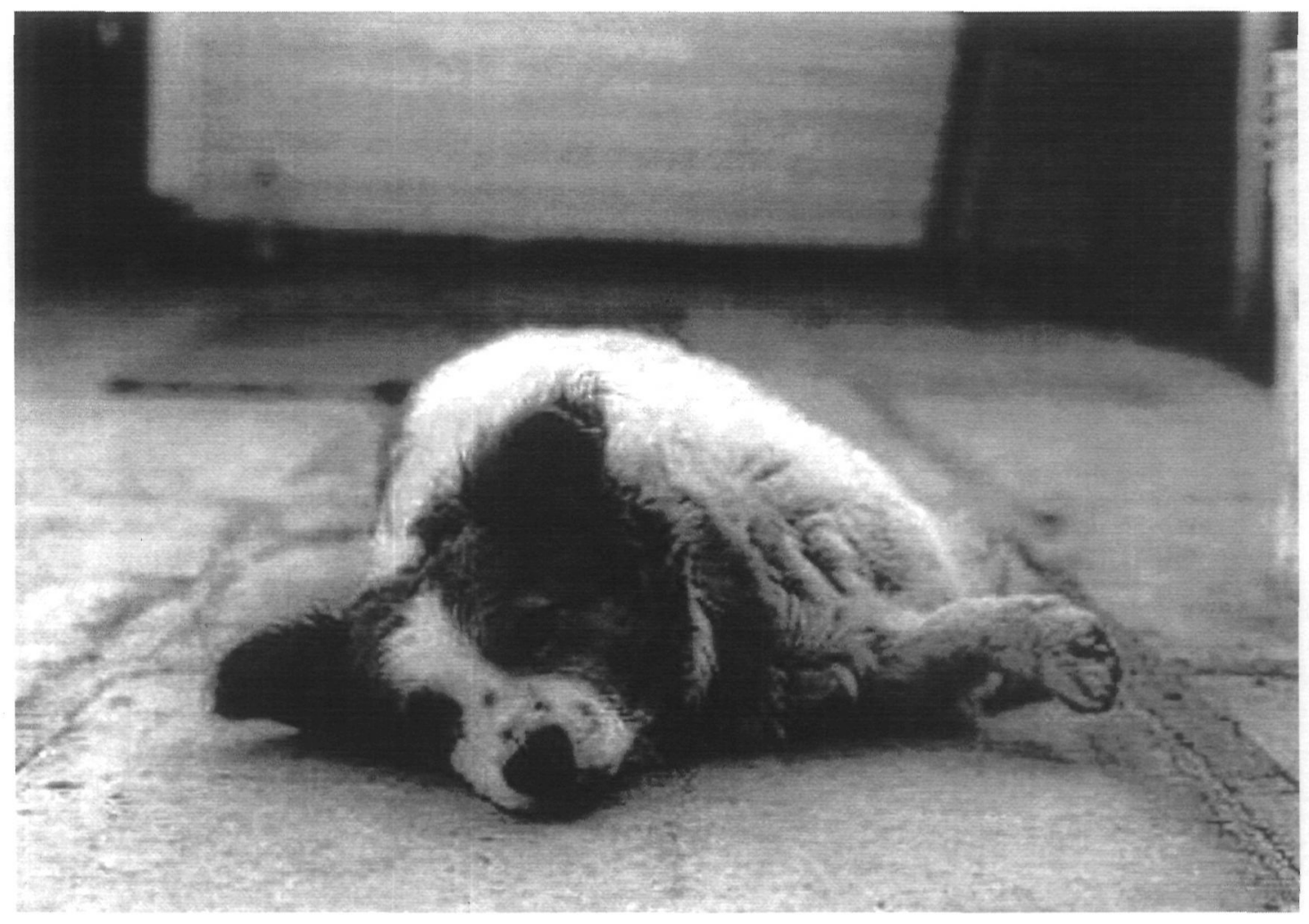


acuerdo con Malinowski (1995 [1922]: 265) los elementos de la realidad se mezclan de forma extraña con fantasías tradicionalmente establecidas, de una forma, no obstante, nada anormal en cualesquiera de las creencias humanas.

Sobre el "funcionamiento" de estas creencias (relación causa- efecto) podemos poner como ejemplo lo que dice el citado Malinowski sobre la eficacia de la magia de los vientos entre los trobriandeses: si bien en una zona de vientos estables y regulares es natural que los hechizos para conseguir vientos favorables sean "efectivos", en un hospital que atiende un gran número de población y que teniendo en cuenta la imprevisibilidad natural del agravamiento de una patología -en un lugar en el que coinciden muchas personas enfermas-, no será poco probable que a una persona gafe se le complique la guardia o que se produzcan dos éxitus consecutivos en la habitación mal fario, por ejemplo.

\section{CONCLUSIONES}

- Todos los resultados obtenidos se centran en un contexto muy localizado: resultaría interesante llevar a cabo este trabajo en un marco cultural y geográfico distinto en el cuál poder analizar y contrastar si hechos similares son exclusivos del contexto observado, o por el contrario forman parte de un ámbito cultural más amplio.

- Se demuestra una relación entre las creencias, ritos del personal, manifestaciones de religiosidad, peculiaridades de la imaginería religiosa observada... y las características del contexto en el que se manifiestan. Aparecen pues elementos propios de una cultura local y de una cultura del trabajo.

- Para la interpretación de estos resultados obtenidos, podemos adoptar el marco teórico que nos ofrece la teoría funcionalista representada por Malinoswki según el cual los ritos, instituciones, cumplen el objetivo de satisfacer una necesidad humana básica.

- A raíz de los resultados que han proporcionado los "actores", se puede afirmar que la utilización de símbolos y práctica de creencias tienen por objetivo, desde un punto de vista del observador, la satisfacción de la seguridad psicológica de la persona que lo realiza, bien cuando se ve amenazada su integridad física en el caso de los pacientes o como una simbolización de las cargas de trabajo o de la tensión producida por este en el caso del personal; en otros casos sería meramente un producto del contexto como en el caso del "fantasma", del "alma" de la enfermera, etc.

- Se ha observado en numerosos casos que al producirse el alta hospitalaria del paciente éste deja las estampas en la habitación, lo cual nos lleva a plantear la siguiente hipótesis. ¿Si el enfermo se ha curado, las deja para el próximo enfermo o es que ha desaparecido la necesidad de tener esas estampas?. Él poder verificar esta hipótesis es difícil por lo complicado de la situación, ya que es un paciente con el cual se pierde contacto.

- También se ha observado la relación enfermera paciente y personal no asistencial como elemento mutuo de enculturación.

- Se aprecia la existencia de "capillas" en algunas unidades: esto es debido al respeto a las creencias religiosas, aunque en algunos casos no sean compartidas.

- Se evidencia la convivencia no excluyente de dos medios de curación: por un lado la medicina y todo su despliegue científico y técnico, basado en la experiencia empírica, y por otro lado una serie de creencias religiosas e incluso esotéricas en el proceso de curación. Estas últimas llegan incluso a ser consideradas por parte de un personal claramente influenciado por su formación biomédica como elementos influyentes en la curación del paciente, como se ha podido demostrar en las entrevistas mantenidas. Como dijo un médico de urgencias en cierta ocasión "a veces las palabras curan más que la penicilina".

\section{AGRADECIMIENTOS}

Al profesor D. Santiago Fernández Ardanaz, de la Universidad Miguel Hernández (Elche), tutor de este trabajo. 


\section{BIBLIOGRAFÍA}

DuRKHEIM (1916): Las formas elementales de la vida religiosa. En Bohannan, P. y Glazer, M.: Antropología. Lecturas. Ed. Mc Graw Hill. $2^{\mathrm{a}}$ ed., 1998.

EliADE, M. (1996): Historia de las creencias y de las ideas religiosas. Ed. Herder. Barcelona.

Evans- Pritchard, E. (1965): Las teorías de la religión primitiva. Siglo XXI, Madrid,1991.

GeERTZ. Cl. (1990): La interpretación de las culturas. Ed. Gedisa. Barcelona.

López Gómez, M.D.; López Terol, E.; Pérez LóPeZ, M.; SuCh, J.; VIDAGANY, I. (1999): Estudio de las creencias en torno al nacimiento en una comunidad alicantina (Una cosmovisión en torno al nacimiento). Rev. Cultura de los Cuidados n ${ }^{\circ} 5$. Universidad de Alicante.

MALINOWSKI, B. (1922): Los argonautas del

Pacífico Occidental. Ed. Península. $4^{\mathrm{a}}$ ed. Barcelona, 1995.
Miralles Sangro, MT; Casas, M.F.; González, P. (1997): Elaboración de un trabajo práctico sobre Antropología de los cuidados. Rev. Cultura de los Cuidados $n^{\circ} 2$. Universidad de Alicante.

PAlenzuela, P. (1995): Las culturas del trabajo. Una aproximación antropológica. Rev. Sociología del Trabajo, $\mathrm{n}^{\circ} 24$.

Salazar, M.; Navarro, S.; GonzÁlez, M. (1997): Antropología del embarazo, parto y puerperio en la ciudad de Elche. Rev. Cultura de los Cuidados n². Universidad de Alicante.

TAYLOR, S.J.; BOGDAN, R. (1986): Introducción a los métodos cualitativos de investigación. Ed. Paidós, Buenos Aires.

Van Gennep, A. (1908): Los ritos de paso. Taurus, Madrid, 1986.

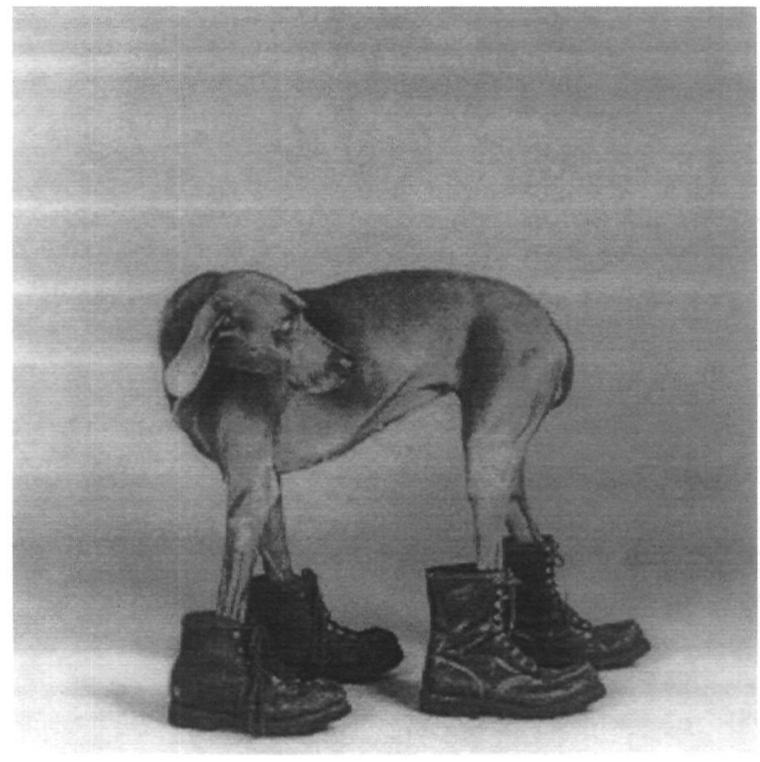

